\title{
FEATURE
}

\section{Format Shift Information Behavior and User Experience in the Academic E-book Environment}

\section{Daniel G. Tracy}

Daniel G. Tracy (dtracy@illinois.edu) is Assistant Professor, Information Sciences and Digital Humanities Librarian University Library, University of Illinois at Urbana-Champaign.

Reference \& User Services Quarterly vol. 58, no. 1, pp. 40-51

(c) 2018 American Library Association. All rights reserved.

Permission granted to reproduce for nonprofit, educational use.
This article seeks to understand information behavior in the context of the academic e-book user experience, shaped by a disparate set of vendor platforms licensed by libraries. These platforms vary in design and affordances, yet studies of e-book use in an academic context often treat e-books as a unified phenomenon in opposition to print books. Based on participant diaries tracking e-book information behavior and follow-up interviews and focus groups on troubleshooting and format shifting behaviors, this study seeks to provide a deep qualitative look at decisions that academic users make about formats when encountering e-books. It identifies reasons for noted disparities between stated user preferences for print books while often using e-books instead. It also demonstrates the importance of considering e-books as a set of formats, rather than a unified experience, when evaluating e-book platforms or providing information services around a set of platforms. While e-book studies often point to a distinction between "use" of e-books and "reading" of print books by users, this study shows much more willingness to both use and read e-books for some tasks if platforms allow for offloading reading of content to preferred reading devices and apps. This has implications for collection development, advocacy with vendors, and for marketing to or consulting with users about e-book access and use options.

$\mathbf{T}$ his study examines information behavior in the context of the academic e-book user experience while taking into account the academic reading environment. This environment includes varying levels of choice in regard to what content users read, what formats are available, and what e-reading devices in reach are compatible with downloadable formats. Users also face variability in whether e-book content is available through library collections, free online copies, online booksellers, or some combination of the three.

Many studies have noted disparities in users' stated preference for print books but relatively high use of e-books or have noted behaviors of shifting from print book to e-book or vice versa. This study investigates the question of why and how academic e-book users make particular decisions in relation to e-book formats when their own preferences and their particular information tasks collide with interfaces and format options over which they have limited control. This environment is the product of intellectual property regimes and the 
competing interests of libraries, publishers, delivery services, and creators of reading devices.

By investigating users' decision making with e-books, this research seeks to deepen the conversation about academic information behavior in relation to e-books, particularly abandoning or avoiding reading of e-book formats (either in favor of print or not reading at all) and the phenomenon of "format shifting." These relate to the relationship between task and technology in information behavior with e-books. Whereas prior literature often treats e-books as a unified entity (asking about preference for e-books versus print, or using only one e-book platform or e-reader to gauge user perceptions about e-books), readers in higher education negotiate a range of platform and device options alongside print. The term format shifting in this article broadly indicates shifts from electronic to print or vice versa, but also and more importantly between electronic formats (reading in a browser interface to reading a downloaded copy in an e-reading app, for example). Understanding format shifting, and how readers connect reading tasks to particular reading format options, has implications for the design of e-book platforms and e-reading devices. It also suggests best practices for the design of library services and the development of collections that shape the e-book user experience. Choosing platforms and pointing to appropriate reading apps to facilitate format shifting should be especially important to librarians who want students and faculty to both use and read e-books-two behaviors often seen as split between e-books and print books.

\section{LITERATURE REVIEW}

Research on e-book use in higher education has focused on e-book adoption by students and faculty and their preferences for e-books versus print equivalents. Many of these studies examine disciplinary differences in adoption and preference, but focus on disciplinary use may obscure other factors. ${ }^{1}$ For example, in their study of e-book transaction logs, Freeman and Saunders found that patterns across disciplines were more similar than different, and that more behavioral variation derives from reading objectives. ${ }^{2}$ Other studies have modeled adoption of e-books, identifying broad factors that inhibit or encourage adoption such as perceived ease of use and perceived usefulness, among others. ${ }^{3}$ Because studies of perception and use, and theorizations of e-book adoption, focus on measuring migration to e-books, they often emphasize marketing to solve problems with awareness or perception. ${ }^{4}$

Awareness, though, may not be the most relevant factor. One recent study suggests interface problems have superseded awareness as the key limitation on e-book use. ${ }^{5}$ Moreover, two studies note greater e-book awareness among humanists despite their relatively constrained adoption of e-books. ${ }^{6}$ Measuring awareness may also be difficult because academic users struggle to distinguish types of electronic content and likely use e-books without being aware that the digital text is an e-book. ${ }^{7}$ In another study, Shrimplin et al. defined four academic e-book user personas-book lovers, technophiles, pragmatists, and printers-that tie level of use to diverse personal attitudes and needs. ${ }^{8}$

Format choice may instead relate to the specific tasks of users. For example, Hillesund's study of expert reading showed that academic readers used e-books for exploratory and fragmented reading but shifted to print for sustained reading. ${ }^{9}$ This distinction has evolved into a common theme in the literature that e-books are used while print books (or printed out e-books) are read. ${ }^{10}$ Reasons for the use of print for more immersive or extended academic reading include highlighting, annotation, and using complicated navigation that users cannot accomplish easily in e-book platforms. ${ }^{11}$ However, Chrzastowski and Wiley emphasize that "uses" under this distinction, even if relatively brief, are still valuable for discovery or other tasks. ${ }^{12}$ Thus they argue that the relatively high frequency of brief uses among humanists as compared to more immersive (reading) uses does not signal low value of e-books for this population. Related to user needs and tasks, D'Ambra, Wilson, and Akter have explored the task-technology fit (TTF) model in relation to e-book use, predicting academic task, technology characteristics, and individual characteristics will shape use of e-books and impact performance. ${ }^{13}$ They found TTF to predict some behavior, particularly for annotation and navigation, but a relatively small amount, and suggested their model may miss relevant factors.

Literature investigating e-book usability suggests the use versus read distinction relates to the disparity between high use of e-books and relative preference for print. E-book platforms pose challenges for advanced reading functionality such as bookmarking, annotation, and comparison of different passages, but allow relatively easy "quick dip" uses such as evaluating the relevance of the text, skimming, and searching. ${ }^{14}$ Thus, preferences for print for more indepth engagement may stem both from some affordances of print formats as well as usability problems with features in e-books even where they have been designed to allow for particular activities such as annotation.

Qualitative or mixed methods studies point to a broader set of e-book information behaviors than the choice between print books and e-books. Thayer et al., while focusing on Kindle use, asked participants to keep reading diaries and conducted follow-up interviews that revealed compensation behaviors for usability challenges. ${ }^{15}$ These behaviors included abandoning reading, adapting to e-reading technology, augmenting e-reading technology with a second reading technology, and off-loading tasks like annotation onto paper. Employing interviews and diaries, Buchanan, McKay, and Levitt looked at digital reading generally (as opposed to e-books specifically) and noted variations in devices used based on the purpose of the reading in addition to shifts to print formats for annotation or most valued uses. ${ }^{16}$ Hobbs and Klare reported on longitudinal interviews followed by a campus-wide survey that showed increasing use of e-books 


\section{FEATURE}

without a matching increase in ease of use. ${ }^{17}$ They noted that students, regardless of e-book experience level, often created elaborate ways to accomplish tasks that the e-book interface rendered difficult to identify and use (e.g., due to unusual icon designs).

As these qualitative dives demonstrate, the discussion of e-books sometimes disguises a broader array of formats and shifts between them, posing a problem for a fuller understanding of e-book behavior. Following the research on connections between task and e-book use in particular, this study takes the relation of user needs, format variation, and particular task contexts as a key point of reference for understanding how the development of e-book platforms, library e-book collections and services, and e-readers all factor into the academic e-book user experience.

\section{METHODOLOGY}

In order to facilitate unobtrusive collection of data about e-book use, participants completed online diaries reporting experiences with e-books over eight weeks (the fifth through twelfth weeks of the fall 2016 semester). Participant diaries are a way to track behavior as it occurs and as frequently as necessary rather than trying to reconstruct or summarize behavior later, without involving an observer who may affect behavior. Any student enrolled in a graduate program at the School of Information Sciences (iSchool) or enrolled in an iSchool graduate course was eligible. The iSchool includes master's degrees in library and information science and in information management, a certificate of advanced study program, and a doctoral program. The study focused on this population due to an earlier transition to library purchase of e-books on related topics to serve a large distance student group (almost half of students, 48.3 percent), and thus captures a population with ample e-book options and the needs of both distance and on campus students. The program also attracts students in a broad swath of disciplines (prominently humanities, social sciences, and computer science). The study would thus gather information from individuals who would exhibit variations in behavior related to discipline (if any).

Participants volunteered by filling out demographic information online. An orientation session familiarized students with the diary forms and included time for questions, which resulted in minor modifications to the forms before reporting began. It also familiarized students with operational definitions of key terms like e-book, use, and avoidance employed by the study in order to help them identify relevant occasions to fill out the diaries and distinguish e-books from other electronic content. Participants received a weekly reminder to ensure that they submitted online diary entries close to actual e-book uses and to reduce the likelihood of participant attrition.

Participants filled out two diary forms as frequently as relevant: one reporting e-book uses or another reporting occasions when they specifically avoided a relevant e-book.
The study defined a use as "any non-accidental opening of an e-book file or e-book website online or on an electronic device or use of a printout from an e-book, or accidental opening of e-book files and websites if the accidental opening leads to any meaningful interaction with the text." The online diary forms gathered information about the title, the relation of the e-book to use of print copies of the same book, different tasks completed with the e-book, the formats in which they used the e-book, and specific features that were easy or challenging to use. It asked only about academic uses, in other words those uses occurring in the course of classes and scholarly research, or other academic labor. Avoidance, for the purposes of this study, refers to purposes where the participant knew an e-book copy was available for content they wanted, but chose not to use the e-book, either in favor of pursuing the same content in print, looking for alternate content, or abandoning the reading altogether. Avoidance diaries asked about the reason they were pursuing the content and for some details about the avoidance, for example if it related to factors outside their control such as broken links or user limits, as well as whether they used a print copy or alternate content instead of the e-book. In cases of broken links or user limits, this means some avoidances were in reality involuntary abandonment of the e-book format, though for convenience this study uses the term avoidance to refer to these diaries as a whole.

Beginning in the second week of the study, select participants were interviewed to discuss particular diary forms as well as their general e-book information behavior. Interview participants were selected purposively to represent diverse challenges and troubleshooting behaviors or uses of multiple formats. Interviews occurred as soon as possible after relevant uses, with reference to diary forms to aid recall. After the diary portion of the study, some additional participants who did not report e-book challenges participated in focus groups to ensure a variety of perspectives. They included a mix of frequent and rare e-book users, none of whom had reported challenges or format shifting with the e-books they used.

After collection, the diary data was supplemented with title information. The diary form asked participants to provide the title or a URL where they retrieved the e-book (such as through the library catalog, a link to a free copy online, or a link to a vendor such as Amazon). This information was used to specify the title, the vendor platform that provided access to the e-book, and the genre of the e-book based on a controlled list. This data was analyzed using descriptive statistics. Interview and focus group recordings were transcribed and coded using a grounded theory approach where the themes emerged from the transcripts using sensitizing concepts of task, decision making, and troubleshooting.

\section{FINDINGS}

A total of 62 students participated in the study. LIS master's students dominated the group (87.1\%), with a handful of 
information management and doctoral students (6.5\% each), although these percentages are proportional to actual differences in student population at the time of the study (the information management degree had just begun with a small first cohort). On campus students (62.9\%) were over-represented and distance students underrepresented although still with substantial participation (37.1\%). Students with a background in the humanities (69.4\%) were most strongly represented, but baseline data is not available for comparison to know whether they were overrepresented. The participants submitted 292 diary entries for e-book use and 52 diary forms for e-book avoidance. However, items identifiable as not e-books (e.g., journal articles) were excluded from analysis, leaving 253 use diaries and 50 avoidance diaries. The median number of valid entries per participant was four, with a mean and mode of five entries per participant. Eight participants entered no valid entries through either diary form-it is unclear how many of these did not use e-books entirely or simply did not report relevant activities, but it was anticipated that at least some students would not encounter e-books during this period.

Examining the use entries more closely, participants reported, on average, four uses each over the eight weeks, with a median of three entries per person and a mode of zero (11 participants). While the reported uses included many brief looks (under 10 minutes), the average estimated use time was 43.1 minutes, with a median and mode of 30 minutes. Approximately half of uses were required course readings, with a quarter of uses also for course assignments besides weekly readings, such as research papers (figure 1). In $79.8 \%$ of cases, the e-book was the only copy used; however, in the other $20.2 \%$ of cases, the participant used a print copy before, after, and/or simultaneously with the e-book: $12.3 \%$ used the e-book after using a print copy, $5.9 \%$ sought a print copy after viewing the e-book, and 5.9\% used print and electronic copies simultaneously (total greater than 20.2\% because participants could choose more than one option). Most uses included an Internet browser as part of the process, but many also included a download of a chapter or the whole e-book, with very few uses including printing of content (table 1). Of the uses reported, 19.0\% involved at least two e-book or e-book-derived (e.g., printed from the e-book) formats, and a handful (2.8\%) used three (browser version, a downloaded copy, and a printout from the e-book).

Participants engaged in a wide variety of tasks in the course of each reported use (table 2); 78.3\% of uses involved more than one task. Most participants found the e-book, on the occasion they reported it, to be very easy or easy to use and reported being either satisfied or very satisfied (figure 2 , figure 3). However, some participants (7.9\%) stopped using the e-book entirely because of usability problems they identified, and a similar number (7.5\%) had problems accessing the e-book to start with because of broken links or user seat limits. A single library e-book platform, Safari, accounted for over half of the seat limit problems, and the same platform accounts for the largest number of neutral responses regarding both satisfaction and ease of use.

Slightly over one-third of participants (37.1\%) reported at least one time that they avoided an e-book that they knew about and wanted to use, accounting for approximately one in every six encounters with e-books reported. Most (74.0\%) were required course readings. Exactly half of avoided titles were textbooks, whereas textbooks made up only $28.5 \%$ of used title reports. It was moderately common also to avoid creative works; handbooks, guides, or technical manuals; and monographs. Figure 4 compares the percentage of e-book use diaries to the percentage of e-book avoidance diaries broken down by genre. Some students opted not to use an e-book because they had run into a broken link or user seat limit in a library-licensed resource (18.0\%), and in slightly over half (54.0\%) of all avoidance cases, participants used a print copy of the same title instead. Some participants (16.0\%) substituted another title for the originally desired book, either a print book or e-book.

Thirteen students participated in interviews, and another ten participated in a focus group. They exhibited wide ranging e-book behaviors and preferences, including use across a variety of devices and e-reading apps. Their comments 


\section{FEATURE}

Table 1. Used Formats Reported in Diaries

\begin{tabular}{lcc}
\hline Format & Total $(\boldsymbol{n = 2 5 3 )}$ & Percent \\
Used online in an internet browser & 201 & 79.45 \\
Used downloaded individual pages or sections in an electronic format & 44 & 17.39 \\
Used download/checkout of entire e-book in an electronic format & 44 & 17.39 \\
Used digitized copy of print book that I scanned or someone scanned for me & 7 & 5.14 \\
Used printout of individual pages or sections & 1 & 2.77 \\
Used printout of entire e-book or a "print-on-demand" copy & 5 & 0.40 \\
Other & 1.98 &
\end{tabular}

Table 2. Tasks Completed with E-book

\section{Task (Select All That Apply)}

Skimmed/scanned passages (for the gist, for specific information, etc.)

Read passages in depth (continuous, linear reading of paragraphs)

Used table of contents to find relevant content

Searched full text for keywords

Referred to book contents while writing

Took notes about the text (separate from text—not including annotations)

Compared the book to other documents (print or electronic)

Used index to find relevant content

Annotation of the text (including underlining/highlighting and marginal notes)

Compared passages from different pages of the book

Other

Bookmarked or "dog-eared" pages

Used embedded multimedia (video, audio)

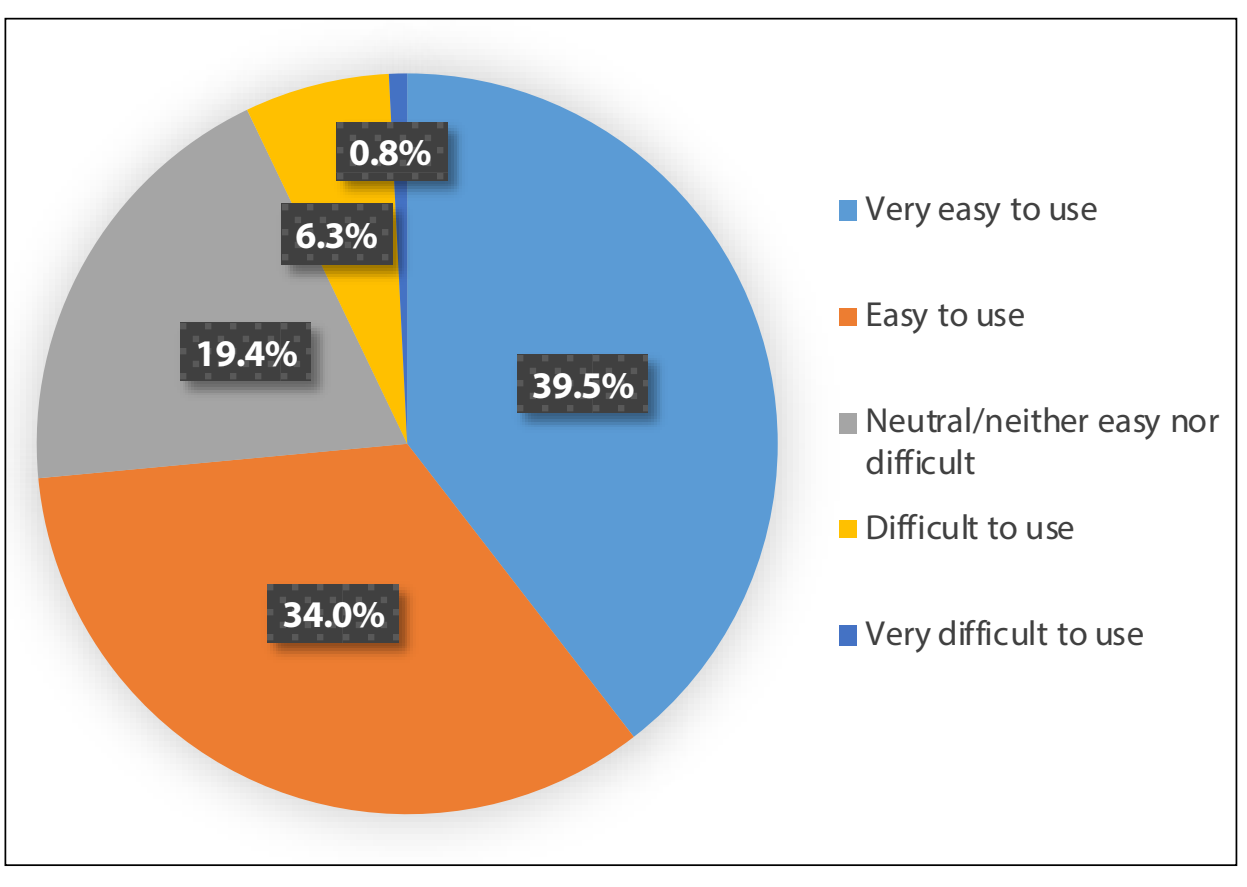

Figure 2. Ease of Use for Individual E-book Uses
Total $(n=253)$

160

$138 \quad 54.5$

$104 \quad 41.1$

80

31.6

65

25.7

54

21.3

39

15.4

32

12.6

$19 \quad 7.5$

11

4.3

9

3.6

6

2.4

0

0.0

produced several themes related to decision-making and e-book information behavior, as described next.

\section{PREFERENCE VERSUS USE}

Participants expressed several reasons contributing to a discrepancy between preferences for one format (almost always print) and use of another (i.e., the e-book). These included the directly economic reason of saving money (lower cost of the e-book copy) in cases where they intended to purchase the title. Two other reasons were pragmatic: saving time because they could use the e-book on short notice, and saving effort. 
In these last cases participants described times when e-books acted as a surrogate for a preferred print copy that was also used but not on hand (because it was forgotten or the e-book was more portable). Some participants also described an ethical rationale for use of e-books, or for choosing not to print sections of e-books; specifically, they believed that e-books were more environmentally friendly due to the reduction in paper use, echoing Bansal..$^{18}$ One user, a self-described artist and sculptor, described a sense that print copies were more convenient than e-books because they were easier to control, and a preference for "touching something, in order to experience it," but at the same time preferred digital reading because "I want to save paper" and had only gone to a paper copy of a recently used book because the e-book interface posed particular usability challenges.

Saving time and effort seemed especially tied to reading requirements: because instructors required some texts, students did not want to invest heavily in them, except in specific cases where they intended to reuse textbooks long-term and thus bought print copies. Several participants noted that their use of e-books despite preference for print books came at the cost of learning and retention, echoing some studies of reading and learning from digital text, or of ease of use. ${ }^{19}$

Only one participant specifically expressed a preference for e-books but used print instead, citing usability challenges that made print more manageable. Others similarly described migration to print for particular uses when frustration with interfaces or functional needs better satisfied by print finally led them to give up on an e-book copy despite the economic and pragmatic incentives.

\section{INTERFACE AND USABILITY: ISOLATION OF TEXT AND INTEGRITY OF THE PAGE}

Many participants wished for better ability to isolate and maximize the text of e-books on screens, whether in a browser or in e-reading apps. They talked of many interfaces having too much "clutter" and excessive functionality that distracted from reading or took up so much screen space that it affected their ability to use the book, especially on smaller screens. "The biggest drawback," one participant noted of a specific interface, "is all the space on the [web]page that is not the book." Browser versions of e-books were the biggest offenders: even linked table of contents on the left side of the screen, one of the most broadly desired features in an e-book interface, could interfere if not retractable. Participants praised interfaces with easy-to-locate and easy-to-use ways of going to a text-only view. A number of participants also described excessive white space as a form of clutter, expressing frustration with e-books showing only short chunks of text with enormous whitespace on each page. These e-books also produced downloadable and print versions with excessive whitespace and unreadably tiny text. Related to the isolation of text, participants also wanted easy-to-use zooming functionality or text resizing.

A related theme to the isolation of text was the integrity of the page. While a couple of participants expressed a sense that equivalents of the printed page (either in PDFs or in browser interfaces) were unimportant, most expressed a strong desire to retain the page as a unit of reading and navigation. Sometimes the desire to isolate text involved a specific desire to view one distinct page on the screen, and many participants desired the ability to "flip" pages rather than scrolling (although this desire was not unanimous). Several participants also mentioned the importance of the integrity of the page for citation purposes in e-books, both locating citations and providing them in their own writing. Interfaces that change pagination as the user resizes text frustrated citation, navigation, and sense of location in the text.

Despite ideas about reimagining the book in publishing, the PDF held particular esteem. Its good reputation came not just from its portability across most e-reading devices, but also from its use of the page in a way that facilitated annotation and navigation in the context of reading apps. PDFs also did not have the same problems with interface clutter except 


\section{FEATURE}

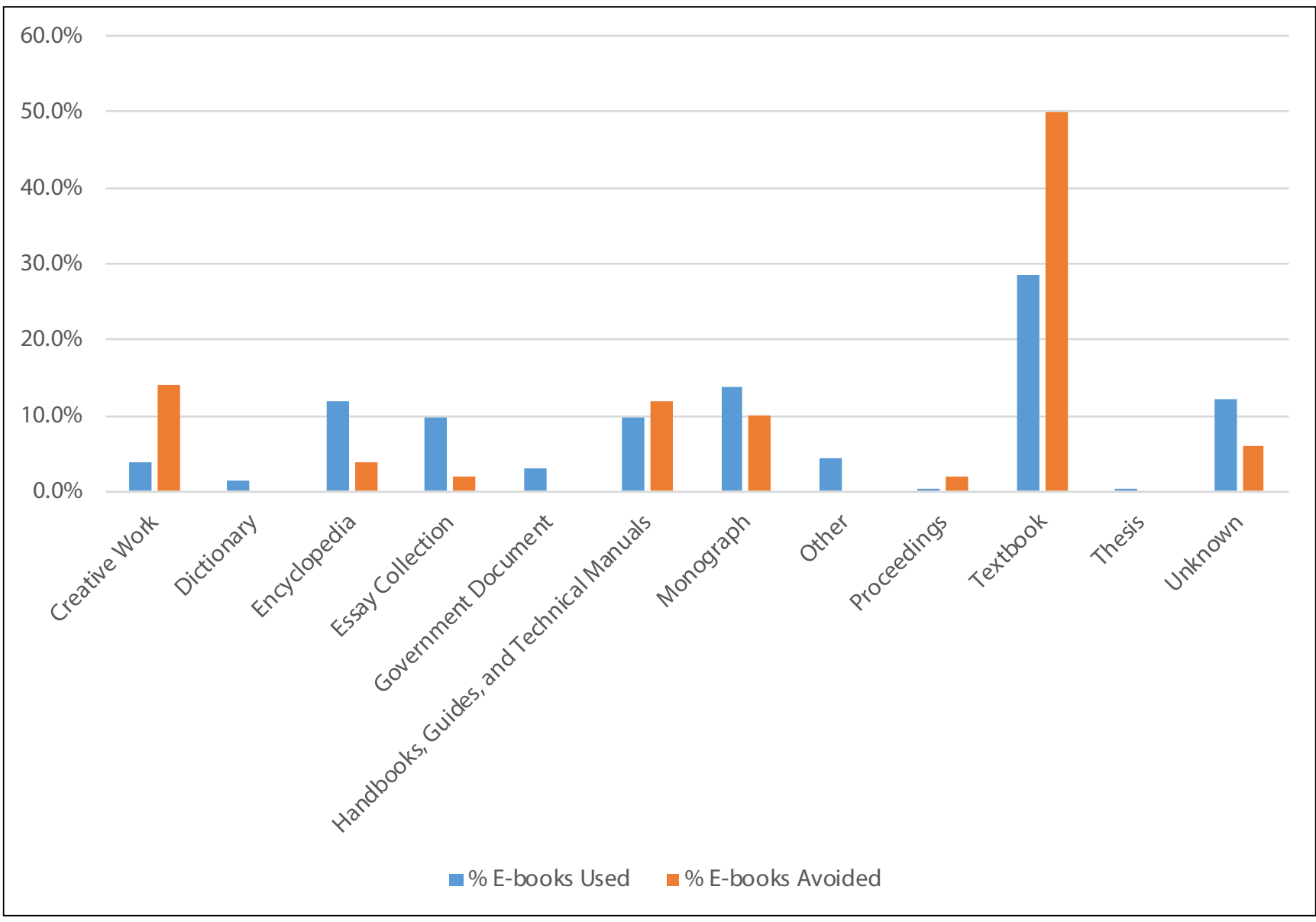

Figure 4. Percentage of E-book Use vs. E-book Avoidance Diaries, by Genre

when presented in a browser interface that introduced the clutter. One user expressed hesitation about longer PDFs: "They're not super easy if you have a bazillion pages to navigate through but on the other hand I don't honestly know if it's that hard either." More generally, participants considered the ability to download PDFs by chapter rather than the whole book as optimal except for the resulting file management challenges with accumulating downloads.

Desired features and navigation challenges also drove the desire for pages. Participants wanted multiple ways to navigate and sift through e-books besides the linked table of contents. If they wanted to be able to isolate the text, they also wanted to be able to have multiple page views of two, four, or more pages at a time to get a visual overview of the text. While PDFs were generally liked, the disconnect between the pagination of many PDFs and the page numbers of the text (due, for example, to front matter not counted in the pagination) caused frustration with navigation. Participants also desired a "back" button, not at the level of the browser page but the book page. They wanted this function in order to make it easy to go back to a distant part of the text you had just come from if you skipped around large portions or consulted an endnote at the back of the text and wanted to return to reading, a behavior participants considered badly supported across familiar platforms and e-reading devices.

\section{FORMATS AND FUNCTION}

Comparing e-books and print books generally, participants described each as better for different tasks consistent with the use-read distinction. Participants valued e-books for full text searching, as a means of evaluating a text for further use, for copying and pasting key information for reuse (including code and equations as well as quotations), and in cases of very short reading (e.g., reference book entries). Participants valued print for navigation, annotation, use with other documents simultaneously, use while writing, extended reading, and tracking the big picture of a complicated text (an activity that brought together navigation, annotation, and extended reading). Several participants went so far as to use both the print and e-book simultaneously, searching the e-book for relevant passages to read in print (although one person described the opposite behavior in a case where searching the e-book was difficult). Some of these cases involved use 
of Google Books, which provides only partial text of incopyright works: "you're able to see like what's going on like the context before and after [your keyword], so then you can make sort of a better decision whether or not that book is like good for whatever you need it for or not." However, others involved full-text e-books available through library-licensed collections or open access online.

One thing e-book interfaces of all kinds could improve is an existing e-book strength: search. While challenges with OCR quality in digitized books did appear, the broader problem with full-text keyword searching was its difficulty to use effectively. ${ }^{20}$ Several participants wanted greater context sensitivity to improve ease of search for common but essential terms. They specifically desired to conduct proximity searches (two or more words on the same page), see the density of appearances of a term across the text rather than working through them individually, and disambiguate keywords with multiple meanings. They also appreciated interfaces that kept search results active while they evaluated specific content and wished this feature were more common. When full-text search did not work well due to OCR problems or because of the need for more context sensitive searching, participants considered flipping through a print book superior, and many saw scrolling to locate relevant material as frustrating and not particularly productive.

Since Shelburne's early work on e-book perceptions and use, much has been made of convenience as a key value of e-books for academic readers. ${ }^{21}$ Participants did indeed describe the portability and ease of access of e-books as important and, as noted above, these features incentivized use of e-books even when participants preferred print. However, participants also emphasized reliability as the countervailing virtue of print. Reliability included the ability to complete traditional reading activities that were more difficult in e-books, a lack of technical difficulties, consistency of access in areas without an internet connection, and a physical presence that meant the book was not forgotten or lost as easily as e-books. Reliability and convenience intersected at times when a few participants described print books as more convenient than e-books precisely due to their reliability. Having to figure out how to access e-books available under different licensing and usability regimes meant print was sometimes more convenient to access, and lack of internet access for non-downloadable titles meant print could be more portable.

While the strengths of print (including the integrity of the page) or the drawbacks of e-books sometimes led participants to print equivalents instead of using an available electronic copy, it rarely led them to print out text from e-books. Instead, they downloaded portions for immersive use. In some cases the lack of printing clearly related to the environmental concerns about use of paper, but more generally it appeared that users treated downloading as the best compromise between the convenience of e-books and the need to complete reading tasks they found more suitable to print, which were at least partially supported by some digital reading apps. The reasons participants described for format shifting from use in a browser to use of a downloaded (usually PDF) e-book were similar to reasons that lead to printing: time-shifting use, extended reading, highlighting, and annotation. The only reasons mentioned for uniquely downloading or printing (as opposed to the other) were reading particularly difficult passages (printing only) and intending to use the e-book multiple times over an extended period (downloading only).

A related key theme throughout the interviews emphasized that participants did not consider all e-book formats to be equal. While HTML text versions of e-books were seen as too tied to the browser to be useful for immersive, extended reading, participants did note that HTML versions often were easiest to use for evaluation purposes before deciding to download a copy for reading, and several liked at least the idea of existing HTML versions that had built-in audiobook functionality. As noted above, though, a PDF exported into a favored reading app could facilitate more extended reading. This reveals how task can relate to choices between e-book format as well as the decision between print and electronic text.

Two interrelated reasons for downloading extended the convenience rationale for using e-books in the first place: time-shifting reading by downloading for later use or ensuring consistency of access when traveling or otherwise unable to access the internet. Indeed, some students emphasized use of both print and electronic copies of the same title, with print used when it was nearby but the e-book used as a surrogate when away from the print. While many users stayed in a browser because they only required quick-dip functionalities like full-text search or quick skimming, others stayed in the browser due to time constraints (skimming reading for class at the last minute) or technical limitations. In general, participants described the lack of ability to download, or to download discrete sections, as a particular failure of the promise of e-book convenience. Digital rights management (DRM) that limited page downloads or printing in a way that required breaking up a chapter received particularly critical comments, as did DRM that prevented downloads entirely or required that checkout downloads of the book be used with Adobe Digital Editions. This software, which erases the book from your computer after the checkout period, was described as difficult to install and use by the handful of participants who had attempted it.

Related to downloadability, portability and interoperability of e-book formats with different devices and software emerged as a major theme. Participants used a wide variety of devices when reading downloaded e-books, including tablets, phones, and occasionally dedicated e-readers like the Kindle (although some mentioned the Kindle as better for pleasure reading), and on these devices they used a range of software that worked best with their individual reading behaviors. The ability to off-load reading from the browser to a preferred reading environment, and possibly more than one preferred reading environment depending on the range of tasks, was paramount in their minds. Similarly, they 


\section{FEATURE}

described the importance of consistent rendering of special (or even standard) characters across devices and software. Annotation, highlighting, and bookmarking simply were not useful in a browser view: despite the fact that several academic e-book vendors have created options for annotation and highlighting that users can save by creating an account, participants universally avoided their use, even when they strongly wanted better annotation functionality. Profile fatigue (exhaustion with too many accounts for too many systems) was a strong disincentive to bother doing so, and browsers were not seen as a useful interface for annotation (for similar findings, see Gale). ${ }^{22}$ One participant dismissed accounts as a deterrent: "There are always like these things that tell you you need to start an account, and I just go ... I'm not making an account to do that." Only a few participants had ever created an academic e-book vendor account, mostly for the option of checking out a DRM-controlled e-book, and all had immediately abandoned it due to disappointment with promised functionality.

\section{DISCUSSION}

Despite orienting participants to a working definition of e-books with examples, about a fifth of participants (12 of 62) filed one or more unnecessary diaries, showing some persistence in challenges to disambiguating electronic resources. Some confusion had to do with an overlap between common e-book and article vendors (e.g., EBSCO and Springer) that do not offer strong visual differentiation between platforms for different types of content. Nonetheless, occasional comments in the interviews also revealed some fluidity between reading behaviors as applied to e-books and electronic scholarly articles.

Format shifting between digital formats or interfaces emerged as a key information behavior lying at the crux of several issues with e-books, including the gap in preference for print versus use of e-books and approaches to troubleshooting. While users sometimes shifted use to print books (or rarely printed out e-book sections), format shifting between different electronic formats, especially from browser views to use on portable devices and in preferred e-reading applications, dominated user behavior. Format shifting in this way served the complementary purposes of escaping usability challenges with browser versions of e-books and movement of the text into a reading environment more conducive to the participants' workflows. Shifting e-book formats to downloaded copies, portable devices, and preferred reading apps serves much the same purpose as shifts to print or printout copies of books. Even if participants preferred print, they treated these downloaded copies as acceptable compromises between the convenience of e-books and the necessity to engage with texts in greater depth. In this sense, the "use rather than read" framework for understanding e-books may be overstated where platforms support easy downloading to offline, non-DRM electronic formats, as approximately a third of uses involved downloading content for use out of the browser. Librarians responsible for selecting titles and formats of books should be aware of what vendors do and do not allow easy downloading of chapters.

The dispersion of devices used by participants as well as the variety of reading needs, and the format shifting behaviors of participants from one electronic format to another, highlight why DRM (and to a lesser extent, HTML-only e-books) is such a problem: the lack of personalization necessary to create an effective e-book reading experience. This finding is counter to arguments often made about DRM and personalization, which are sometimes described as going hand-in-hand: because DRM copies keep readers in a particular platform for all or at least a greater part of their time using a book, often using individual user accounts, individualized data about readers can be used to serve up personalized recommendations or other customized features. ${ }^{23}$ This study, though, shows that DRM-driven attempts at personalization undermine personalization of reading processes. Every DRMdriven platform that requires users to stay within its interface complicates the overall academic e-book user experience by adding unique workflows that are not consistent with default preferred reading apps. In this sense, DRM may inflate the use rather than read phenomenon. By contrast, readers personalize reading by exporting e-books (or chapters) to a preferred reading device to minimize the number of platforms they need to learn to use and to ensure offline access.

Notably, though, e-book convenience also encourages a sense of disposability and lack of reuse. Despite "anytime, anywhere" e-book access, participants wanted print copies for long term reuse, not just because those uses were more complicated but also because e-books are easy to forget about versus print's visual presence on a bookshelf, which could remind participants of their intention to re-use a title. E-books may in this sense decrease further optional uses of the same book content that users would find valuable to revisit, especially if they cannot create a unified personal e-book "library."

This study also provides insight into another feature of academic e-book behavior that few have remarked upon: the ways requirement shapes e-book information behavior. Studies of academic user preferences often highlight willingness to use e-books as a sign academic users in fact prefer them despite statements to the contrary, with little question of whether the users had a choice of using that content. Similarly, occasional studies discuss the importance of various reading tasks in the behavior of participants, but they leave implicit the question of the motivation. ${ }^{24}$ By asking about the reasons for using the e-books, the diary forms recorded various states of intentionality and requirement behind academic reading. Unlike pleasure reading, where choice of a particular title is nearly always optional (or otherwise easily delayed until a later date), academic reading usually has some degree of requirement. This requirement may come from an external individual, such as an instructor assigning readings available in some formats but not others. However, in longer research 
papers in courses or especially in non-course research, the requirement is inherent in the obligation to complete a responsible literature review. The qualitative data suggested external requirements (i.e., from instructors) increase use but specifically increase the quick dip uses associated with the use versus read phenomenon. Downloadability, then, may increase in importance as reading becomes less determined by instructor demand and more by choice for individual research projects, especially outside the classroom.

The diary data did indicate that a handful of users abandoned e-books early rather than finishing reading due to poor usability or lack of downloadability. One interviewee noted, "if it's not downloadable . . . if I don't really, really have to read it, like I'm likely to say, well . . . I guess I'm not using that." Abandonment was relatively unusual, though, and the interviewee's comment about choice is important in the context of academic e-book use. If libraries purchase e-books instead of print titles, as many do, then some of the resulting use will be a matter of lack of choice if there is not a print copy users feel they can afford to purchase. Abandonment seems most likely for course-required readings in an e-book format if the usability problems are substantial or users prefer print. As noted above, textbooks as a genre accounted for a higher percentage of instances of avoidance than instances of use, and that is true of all books used for course requirements beyond textbooks. Although course-required texts were the most prevalently used titles, accounting for about half of all uses (50.2\%), they accounted for nearly three-quarters (74.0\%) of all instances of e-book avoidance. Notably, while some of these avoidances led to acquisition of a print copy, many of these avoidances simply led to not completing the reading in any format.

In contrast to academic reading, where participants use e-books despite a preference for print, most interviewees who mentioned pleasure reading noted that they are happier to read books for fun as e-books rather than in print. This finding is consistent with Melcher but contrary to most other studies of academic e-book users. ${ }^{25}$ The main factor participants connected to this willingness to read for pleasure in e-books was that they did not need to interact with the text as deeply as for learning purposes, and they found e-reading devices for pleasure reading (primarily the Kindle) suitable to their needs.

\section{CONCLUSION}

This study suggests that e-book research premised primarily on a comparison of preferences and use of print books versus e-books, without regard to variation in e-book platforms and their affordances, may miss essential features of the e-book environment. Information behavior in relation to e-book content in an academic environment has evolved in tandem with a variety of platforms, devices, and software for e-book reading that provide significantly different experiences. Economic, usability, and ethical issues may override preferences for e-books or print books. The general lack of choice in whether or not to read a particular title in an academic context (because it is assigned or necessary for understanding a research area) may be especially important in driving use of academic e-books when print is preferred, particularly when print copies are checked out or unowned by libraries.

This study has important implications for the design and delivery of platforms for academic e-books for which librarians should advocate on behalf of users. Platforms and apps could improve interfaces by minimizing clutter, enhancing search, and easing the ability to go to a text-only view and flip to larger navigational views. More crucially, downloadability (by chapter) and portability (offline, and to different reading apps) of e-book content are fundamental to the idea of e-book convenience held by academic users as well as to personalization of e-book reading behavior. Librarians may also want to refrain from marketing or recommending vendor-specific reading apps given the general sense of users that the e-reading landscape is already too cluttered. Rather, highlighting reading apps that will work for downloaded content from many different vendors may be a better service for users.

For librarians, DRM-heavy platforms provide reason for caution, and librarians should be skeptical of any functionality that requires special accounts due to users' lack of willingness to create them. Download page limits that force users to break up chapters should be avoided. Monographs in particular may be worth avoiding in e-book format when they are not DRM-free and available for download into users' preferred reading environments. Textbooks may be the best case for libraries buying both print book and e-book copies of a title. Some users simply are not comfortable with textbook reading in e-book format, but it can save money for those who are, and there is significant use of textbooks for quick-reference outside of assigned class readings that may be equally important in driving high use of those titles. However, many users will simply buy their own copy of a textbook because they see it as a long-term investment that they will use beyond the semester.

Most broadly, this study suggests that for some readers the use versus read distinction is fading for e-books when users can find platforms that allow downloadability and portability that allow them to move to preferred reading devices and apps. Few e-reading interfaces have been able to capture the full complexity of using and reading activities that people need to pursue for academic work, but the ability to migrate between interfaces is key to e-books as a service to users. Librarians should keep this in mind when talking to platform providers, choosing platforms for e-books, and talking to their users about options for reading interfaces and access.

\section{ACKNOWLEDGEMENTS}

The author wishes to acknowledge the Research and Publication Committee of the University of Illinois at 


\section{FEATURE}

Urbana-Champaign Library, which provided support for the completion of this research. Thank you to Lydia Frank for the transcription of interview and focus group recordings and supplementary curation of the diary data set. The author is also grateful to several individuals for providing feedback on drafts of the article in progress, including Sarah Christensen, Jodi Schneider, Heather Simmons, Janet Swatscheno, and Mara Thacker.

\section{References}

1. Steven A. Knowlton, "A Two-Step Model for Assessing Relative Interest in E-books Compared to Print," College $E$ Research Libraries 77, no. 1 (January 2016): 20-33, https://doi .org/10.5860/crl.77.1.20; Michael Levine-Clark, "E-book Usage on a Global Scale: Patterns, Trends and Opportunities," Insights 28, no. 2 (July 2015): 39-48, https://doi.org/10.1629/uksg.240; Carol Simon, "Just the Facts: An Examination of E-book Usage by Business Students and Faculty," Reference Librarian 52, no. 3 (July 2011): 263-73, https://doi.org/10.1080/02763877.2011 .556561

2. Robert S. Freeman and E. Stewart Saunders, "E-book Reading Practices in Different Subject Areas: An Exploratory Log Analysis," in Academic E-books: Publishers, Libraries, and Users, ed. Suzanne M. Ward, Robert S. Freeman, and Judith M. Nixon (West Lafayette, IN: Purdue University Press, 2016), 133-46.

3. Noa Aharony, "The Effect of Personal and Situational Factors on LIS Students' and Professionals' Intentions to Use E-books," Library \& Information Science Research 36, no. 2 (April 2014): 106-13, https://doi.org/10.1016/j.lisr.2014.01.001; Noa Aharony, "Factors Affecting the Adoption of E-books by Information Professionals," Journal of Librarianship and Information Science 47, no. 2 (June 1, 2015): 131-44, https://doi .org/10.1177/0961000614532120; Chang-Hyun Jin, "Adoption of E-book among College Students: The Perspective of an Integrated TAM," Computers in Human Behavior 41 (December 2014): 471-77, https://doi.org/10.1016/j.chb.2014.09.056; Eunil Park, Jungyeon Sung, and Kwangsu Cho, "Reading Experiences Influencing the Acceptance of E-book Devices," Electronic Library 33, no. 1 (2015): 120-35, https://doi.org/10.1108/EL-052012-0045; Malathi Letchumanan and Balakrishnan Muniandy, "Migrating to E-book: A Study on Perceived Usefulness and Ease of Use," Library Hi Tech News 30, no. 7 (2013): 10-16, https://doi .org/10.1108/LHTN-05-2013-0028; Clive Sanford, "An Artifact Switching Model for User Acceptance of Ebooks," Journal of Organizational and End User Computing 25, no. 2 (April 2013): 19-40, https://doi.org/10.4018/joeuc.2013040102; I. Tri-Agif, A. Noorhidawati, and S. Ghazal Ghalebandi, "Continuance Intention of Using E-book among Higher Education Students," Malaysian Journal of Library \& Information Science 21, no. 1 (January 2016): 19-33.

4. Aharony, "Factors Affecting the Adoption of E-books by Information Professionals"; Linda Ashcroft, "Ebooks in Libraries: An Overview of the Current Situation," Library Management 32, no. 6/7 (September 2011): 398-407, https://doi .org/10.1108/01435121111158547; Cynthia L. Gregory, "But I Want a Real Book': An Investigation of Undergraduates' Usage and Attitudes toward Electronic Books," Reference \& User Services Quarterly 47, no. 3 (Spring 2008): 266-73; LevineClark, "E-book Usage on a Global Scale"; Melissa Raynard, "Understanding Academic E-books through the Diffusion of Innovations Theory as a Basis for Developing Effective Marketing and Educational Strategies," Journal of Academic Librarianship 43, no. 1 (January 2017): 82-86, https://doi.org/10.1016/j acalib.2016.08.011; Yingqi Tang and Paula Barnett-Ellis,
"Nursing Students' Learning Experience With E-books," Journal of Academic Librarianship 43, no. 1 (January 2017): 67-71.

5. Alexander J. Carroll et al., "E-book Perceptions and Use in STEM and Non-STEM Disciplines: A Comparative Follow-Up Study," January 2016, https://doi.org/10.13016/M24Q38.

6. Michael Levine-Clark, "Electronic Books and the Humanities: A Survey at the University of Denver," Collection Building 26, no. 1 (February 2007): 7-14, https://doi .org/10.1108/01604950710721548; Tao Zhang and Xi Niu, "The User Experience of E-books in Academic Libraries: Perception, Discovery, and Use," in Academic E-books: Publishers, Libraries, and Users, 2016.

7. Kendall Hobbs and Diane Klare, "Are We There Yet? A Longitudinal Look at E-books through Students' Eyes," Journal of Electronic Resources Librarianship 28, no. 1 (January 2016): 9-24, https://doi.org/10.1080/1941126X.2016.1130451; Wendy Allen Shelburne, "E-book Usage in an Academic Library: User Attitudes and Behaviors," Library Collections, Acquisitions \& Technical Services 33, no. 2/3 (June 2009): 59-72, https://doi .org/10.1016/j.lcats.2009.04.002.

8. Aaron K. Shrimplin et al., "Contradictions and ConsensusClusters of Opinions on E-books," College $\&$ Research Libraries 72 , no. 2 (March 2011): 181-90, https://doi.org/10.5860/crl-108rl.

9. Terje Hillesund, "Digital Reading Spaces: How Expert Readers Handle Books, the Web and Electronic Paper," First Monday 15, no. 4 (April 2010), https://doi.org/10.5210/fm.v15i4.2762.

10. Jeff Staiger, "How E-books Are Used," Reference \& User Services Quarterly 51, no. 4 (Summer 2012): 355-65.

11. Selinda Adelle Berg, Kristin Hoffmann, and Diane Dawson, "Not on the Same Page: Undergraduates' Information Retrieval in Electronic and Print Books," Journal of Academic Librarianship 36, no. 6 (November 2010): 518-25, https://doi.org/10.1016/j acalib.2010.08.008; Laura Muir and Graeme Hawes, "The Case for E-book Literacy: Undergraduate Students' Experience with E-books for Course Work," Journal of Academic Librarianship 39, no. 3 (May 2013): 260-74, https://doi.org/10.1016/j acalib.2013.01.002; M. Cristina Pattuelli and Debbie Rabina, "Forms, Effects, Function: LIS Students' Attitudes towards Portable E-book Readers," in Aslib Proceedings, vol. 62 (Emerald Group Publishing Limited, 2010), 228-244, https://doi .org/10.1108/00012531011046880.

12. Tina E. Chrzastowski and Lynn N. Wiley, "E-book Use and Value in the Humanities," Library Resources \& Technical Services 59, no. 4 (October 2015): 172-86, https://doi.org/10.5860 /lrts.59n4.172

13. John D’Ambra, Concepción S. Wilson, and Shahriar Akter, "Application of the Task-Technology Fit Model to Structure and Evaluate the Adoption of E-books by Academics," Journal of the American Society for Information Science \& Technology 64, no. 1 (January 2013): 48-64, https://doi.org/10.1002/asi.22757.

14. Caroline Gale, "Champions and E-books: Using Student Library Champions to Inform E-book Purchasing Strategies," Insights 29, no. 2 (July 5, 2016), https://doi.org/10.1629/uksg.299; Julie Gilbert and Barbara Fister, "The Perceived Impact of E-books on Student Reading Practices: A Local Study," College \& Research Libraries 76, no. 4 (May 2015): 469-89, https://doi.org/10.5860 /crl.76.4.469; Hobbs and Klare, "Are We There Yet?"

15. Alexander Thayer et al., "The Imposition and Superimposition of Digital Reading Technology: The Academic Potential of E-readers," in Proceedings of the SIGCHI Conference on Human Factors in Computing Systems, CHI '11 (New York: ACM, 2011), 2917-26, https://doi.org/10.1145/1978942.1979375.

16. George Buchanan, Dana McKay, and Joanna Levitt, "Where My Books Go: Choice and Place in Digital Reading," in Proceedings of the 15th ACM/IEEE-CS Joint Conference on Digital Libraries, JCDL '15 (New York: ACM, 2015), 17-26, https://doi .org/10.1145/2756406.2756917. 
17. Hobbs and Klare, "Are We There Yet?"

18. Gaurav Bansal, "E-book Usage: Role of Environmental Consciousness, Personality and Past Usage," Journal of Computer Information Systems 52, no. 2 (December 1, 2011): 93-104, https://www.tandfonline.com/doi/abs/10.1080/08874417.2011 .11645544 .

19. Lauren M. Singer and Patricia A. Alexander, "Reading on Paper and Digitally: What the Past Decades of Empirical Research Reveal," Review of Educational Research 87, no. 6 (2017), 1007-41, http://doi.org/10.3102/0034654317722961.

20. Tao Zhang, Xi Niu, and Marlen Promann, "Assessing the User Experience of E-books in Academic Libraries," College E Research Libraries 78, no. 5 (2017): 578-601, https://doi .org/10.5860/crl.78.5.578.

21. Shelburne, "E-book Usage in an Academic Library." For a more recent example as applied to humanists, see Chrzastowski and Wiley, "E-book Use and Value in the Humanities."

22. Gale, "Champions and E-books."
23. N. Hameed, Y.-N Cheah, and M. Rafie, "An E-book Personalization Architecture with Digital Rights and Encryption Procedures," in 2010 International Symposium on Information Technology, vol. 3, 2010, 1222-27, https://doi.org/10.1109/ITSIM.2010.5561626.

24. D'Ambra, Wilson, and Akter, "Application of the Task-Technology Fit Model to Structure and Evaluate the Adoption of E-books by Academics"; Freeman and Saunders, "E-book Reading Practices in Different Subject Areas: An Exploratory Log Analysis."

25. Amanda Melcher, "ATG Special Report: Academic Library Survey on Ebooks and Ebook Readers," Against the Grain 27, no. 1 (February 2015): 60-64; Carroll et al., "E-book Perceptions and Use in STEM and Non-STEM Disciplines"; Chris Gibson and Forbes Gibb, "An Evaluation of Second-Generation Ebook Readers," Electronic Library 29, no. 3 (June 2011): 303-19, https://doi .org/10.1108/02640471111141061; Shrimplin et al., "Contradictions and Consensus-Clusters of Opinions on E-books." 